\title{
Acute spontaneous unilateral adrenal hemorrhage: etiology and imaging findings in six cases
}

Hemorragia adrenal unilateral espontânea aguda: etiologia e achados de imagem em seis casos

\section{Isa Félix Adôrno ${ }^{1, a}$, Tiago Kojun Tibana ${ }^{1, b}$, Guilherme Castilho Sorensen de Lima ${ }^{2, c}$, Leticia de Assis Martins ${ }^{3, d}$, Walberth Gutierrez Junior ${ }^{1, e}$, Suzan Menasce Goldman ${ }^{2, f}$, Thiago Franchi Nunes ${ }^{1, \mathrm{~g}}$}

1. Hospital Universitário Maria Aparecida Pedrossian da Universidade Federal de Mato Grosso do Sul (HUMAP-UFMS), Campo Grande, MS, Brazil. 2. Escola Paulista de Medicina da Universidade Federal de São Paulo (EPM-Unifesp), São Paulo, SP, Brazil. 3. MS Diagnósticos Médicos, Campo Grande, MS, Brazil.

Correspondence: Dr. Thiago Franchi Nunes. Avenida Senador Filinto Muller, 355, Vila Ipiranga. Campo Grande, MS, Brazil, 79080-190. Email: thiagofranchinunes@gmail.com.

a. https://orcid.org/0000-0002-2106-1211; b. https://orcid.org/0000-0001-5930-1383; c. https://orcid.org/0000-0002-6126-2309; d. https://orcid.org/0000-0002-5475-8787; e. https://orcid.org/0000-0002-9798-221X; f. https://orcid.org/0000-0002-3596-3419; g. https://orcid.org/0000-0003-0006-3725.

Received 16 March 2018. Accepted after revision 16 April 2018.

How to cite this article:

Adôrno IF, Tibana TK, Sorensen de Lima GC, Martins LA, Gutierrez Junior W, Goldman SM, Nunes TF. Acute spontaneous unilateral adrenal hemorrhage: etiology and imaging findings in six cases. Radiol Bras. 2019 Jan/Fev;52(1):12-16.

Abstract Objective: To evaluate the computed tomography characteristics of patients admitted with clinical suspicion of acute adrenal hemorrhage at three centers over a 3-year period and in whom that diagnosis was ultimately confirmed.

Materials and Methods: This was a retrospective analysis of computed tomography findings in patients with suspected acute adrenal hemorrhage. We included only those cases in which the diagnosis was confirmed. Patients with aortic rupture and retroperitoneal hemorrhage were excluded. The images were analyzed by an experienced radiologist and by two radiology residents.

Results: Six cases of unilateral adrenal hemorrhage (three on the left and three on the right) were analyzed. On computed tomography, each appeared as a rounded, oval mass altering the usual anatomy of the adrenal gland. The maximum diameter was 12.2 $\mathrm{cm}$, and attenuation ranged from 45 to $70 \mathrm{HU}$. There was no appreciable contrast enhancement. No calcifications were observed. Conclusion: Adrenal hemorrhage, albeit rare, is potentially fatal. Early diagnosis is essential. Therefore, recognition of the possible presentations of these lesions by radiologists may help prevent hemorrhage from progressing to adrenal insufficiency and death.

Keywords: Adrenal glands; Hemorrhage; Tomography, X-ray computed.

Resumo Objetivo: Avaliar as características de imagem na tomografia computadorizada de pacientes admitidos com suspeita clínica de hemorragia adrenal aguda em três instituições, no período de três anos, e que tiveram o diagnóstico final confirmado.

Materiais e Métodos: Análise retrospectiva da tomografia computadorizada de pacientes com suspeita de hemorragia adrenal aguda. Foram incluídos apenas os casos com confirmação diagnóstica. Foram excluídos os pacientes que apresentaram ruptura aórtica e hemorragia retroperitonial. As imagens foram analisadas por um radiologista experiente e dois residentes em radiologia. Resultados: Este estudo analisou seis casos de hemorragia adrenal unilateral, três deles na adrenal esquerda e três na adrenal direita. Todos apresentaram-se com massa arredondada ou oval, alterando a anatomia habitual da glândula. 0 diâmetro máximo foi $12,2 \mathrm{~cm}$ e os valores de atenuação variaram de 45 a $70 \mathrm{UH}$, não se observando realce nas fases contrastadas. Não foram observadas calcificações.

Conclusão: As hemorragias adrenais são raras, porém, potencialmente fatais. O diagnóstico precoce é essencial, portanto, o reconhecimento das possíveis apresentações dessas lesões pelos radiologistas pode ajudar a evitar que pacientes evoluam com insuficiência da glândula e óbito.

Unitermos: Glândula adrenal; Hemorragia; Tomografia computadorizada.

\section{INTRODUCTION}

Adrenal hemorrhage, albeit rare, is potentially fatal. The adrenal glands are particularly prone to hemorrhage, because of their abundant blood supply coming from three arteries that drain into a single vein, which may undergo vasoconstriction in response to the catecholamines excreted by the adrenal medulla ${ }^{(1)}$. This may occur in several conditions, including trauma, bleeding disorders, infection, stress, and bleeding from an adjacent adrenal tumor ${ }^{(2,3)}$.
Historically, given the absence of a specific clinical presentation, adrenal hemorrhage has often been suspected or diagnosed only at autopsy. Early diagnosis, in the acute or chronic stages ${ }^{(4,5)}$, has now become possible through advances in imaging techniques. Up to $50 \%$ of patients with bilateral adrenal hemorrhage eventually develop adrenal insufficiency with an increased risk of death ${ }^{(6,7)}$, making early diagnosis important. The recognition of bleeding secondary to adjacent tumors is also important, 
so that patients with masses, such as pheochromocytoma, do not go untreated. Despite the relevance of adrenal hemorrhage and the fundamental role of imaging studies, there are relatively few publications that cover this subject in the radiology literature ${ }^{(8)}$.

We analyzed images of patients who underwent computed tomography (CT), with suspicion of acute unilateral adrenal hemorrhage, who been admitted to one of three emergency departments. We evaluated the etiology of each case and the various characteristics of the lesions on the CT scan.

\section{MATERIALS AND METHODS}

This was a retrospective study of patients with suspected unilateral adrenal hemorrhage who underwent CT in one of three emergency radiology departments between January 2015 and January 2018. Patients with aortic rupture and traumatic or iatrogenic retroperitoneal hemorrhage were excluded from the study, and the final sample comprised six patients (three females and three males). The study was approved by the institutional ethics committee (CAAE: 014830018.2.0000.0021).

All patients were examined on multidetector CT scanners-Aquilion 64 (Toshiba Medical Systems, Otawara, Japan), Lightspeed 64 (GE Healthcare, Chicago, IL, USA), or Somatom (Siemens Healthcare, Erlangen, Germany)with acquisitions in the pre-contrast phase, followed by a multiphase study after the intravenous infusion of contrast medium $(4-5 \mathrm{~mL} / \mathrm{s})$. The multiphase study consisted of an arterial phase, using the bolus-tracking technique, followed by a portal phase ( $70 \mathrm{~s}$ after contrast medium injection). A late phase (180-300 s) was performed in four of the six patients, in order to characterize vascular lesions or differentiate between vascular lesions and normal variants of the urinary tract anatomy. Post-processing techniques included multiplanar reconstruction and maximum intensity projection.

Two radiology residents and a radiologist with seven years of experience in abdominal imaging analyzed the imaging studies, observing the laterality and configuration of the adrenal lesions, as well as carrying out measurements to determine the size of the largest axis, the estimated volume, the density after pre-contrast acquisitions, the enhancement pattern, the presence or absence of calcifications, and the characteristics of the margins. Clinical records and outcomes were also analyzed. All of the data collected were entered into a Microsoft Excel 2016 spreadsheet. Adrenal hemorrhage is defined here as a solid formation, which in the pre-contrast phase presents a density greater than or equal to $40 \mathrm{HU}$ or the absence of enhancement in the post-contrast phases ${ }^{(8)}$.

\section{RESULTS}

\section{Findings on CT}

The CT examinations revealed an adrenal mass, preventing the identification of the normal anatomy of the gland. The lesion appeared as a rounded mass with margins that were partially well-defined in one case (Figure 1); regular and well defined in three cases; and irregular in two cases. The lesion was in the left adrenal gland, with a mean diameter of $6 \mathrm{~cm}$ (range, 3-12.5 cm), in three cases and in the right adrenal gland, with a mean diameter of $7.8 \mathrm{~cm}$ (range, 6-12.2 cm), in the three remaining cases. The adrenal mass attenuation values ranged from $45 \mathrm{HU}$ to $70 \mathrm{HU}$ in noncontrast scans; in cases in which nonionic iodinated contrast agent was injected, no enhancement was observed. No calcifications were observed in any of the cases (Table 1).

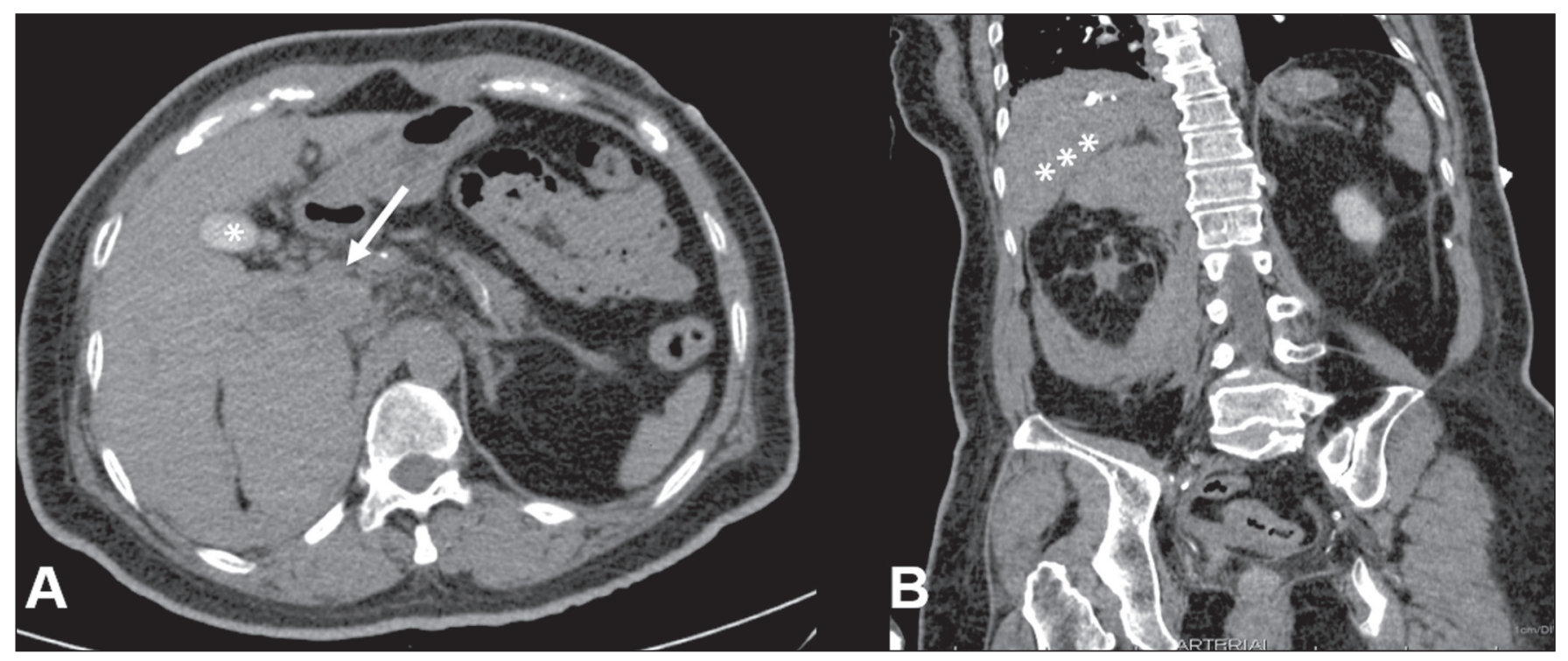

Figure 1. A: Axial CT scan with no intravenous contrast showing an adrenal mass on the right (arrow), with partially well-defined margins, measuring $9.5 \times 7.5$ $\times 6.5 \mathrm{~cm}$, and spontaneously hyperattenuated $(65 \mathrm{HU})$. Gallbladder containing contrast medium because of prior cardiac catheterization (asterisk). B: Coronal CT scan showing no enhancement in the post-contrast phase and cranial displacement of the adjacent hepatic border (asterisks). 
Table 1-Characteristics of adrenal lesions.

\begin{tabular}{|c|c|c|c|c|c|c|c|}
\hline Patient & Gender & $\begin{array}{c}\text { Age } \\
\text { (years) }\end{array}$ & Side & $\begin{array}{l}\text { Largest } \\
\text { diameter } \\
\quad(\mathrm{cm})\end{array}$ & $\begin{array}{l}\text { Volume } \\
\text { (mL) }\end{array}$ & $\begin{array}{l}\text { Pre-contrast } \\
\text { density } \\
(\mathrm{HU})\end{array}$ & Margins \\
\hline 1 & $\mathrm{~F}$ & 72 & $\mathrm{R}$ & 9.5 & 240 & 65 & $\begin{array}{l}\text { Partially } \\
\text { defined }\end{array}$ \\
\hline 2 & M & 89 & $\mathrm{~L}$ & 12.1 & 505 & 45 & Well-defined \\
\hline 3 & $\mathrm{~F}$ & 64 & $\mathrm{~L}$ & 3.9 & 12 & 53 & Well-defined \\
\hline 4 & $\mathrm{~F}$ & 58 & L & 3.0 & 13 & 45 & Irregular \\
\hline 5 & $M$ & 55 & $\mathrm{R}$ & 12.2 & 700 & 70 & Well-defined \\
\hline 6 & M & 43 & $\mathrm{R}$ & 6.0 & 74 & 55 & Irregular \\
\hline
\end{tabular}

F, female; M, male; R, right; L, left.

\section{Clinical data, etiology, and outcomes}

The etiologies included hemophilia (Figure 2), arterial hypertension with hypertensive peaks (Figure 3), sepsis, hepatocellular carcinoma metastasis, and cardiac catheterization. Signs and symptoms included the following: severe hypotension, in a patient with a clinical history of shock due to adrenal insufficiency; chronic anemia, in a patient with palpable abdominal mass; left back pain, in a patient with arterial hypertension; associated septic shock, in a patient with an infected eschar and bacterial pneumonia; abdominal pain, in a patient with hepatocellular carcinoma; and lumbar pain, in a dialysis patient who received renal transplantation (Figure 4). The laboratory test results showed cortisol within the limits of normality in five patients and alterations characteristic of adrenal insufficiency in the remaining patient. No biopsy or surgical resection was performed in any of the cases. The watchful waiting approach was used in three patients, whereas one patient received intravenous corticosteroid therapy, one underwent surgical resection, and one died (Table 2).

\section{DISCUSSION}

Unilateral spontaneous adrenal hemorrhage is an uncommon surgical emergency that can present as massive retroperitoneal hemorrhage and is potentially fatal ${ }^{(9)}$. Its

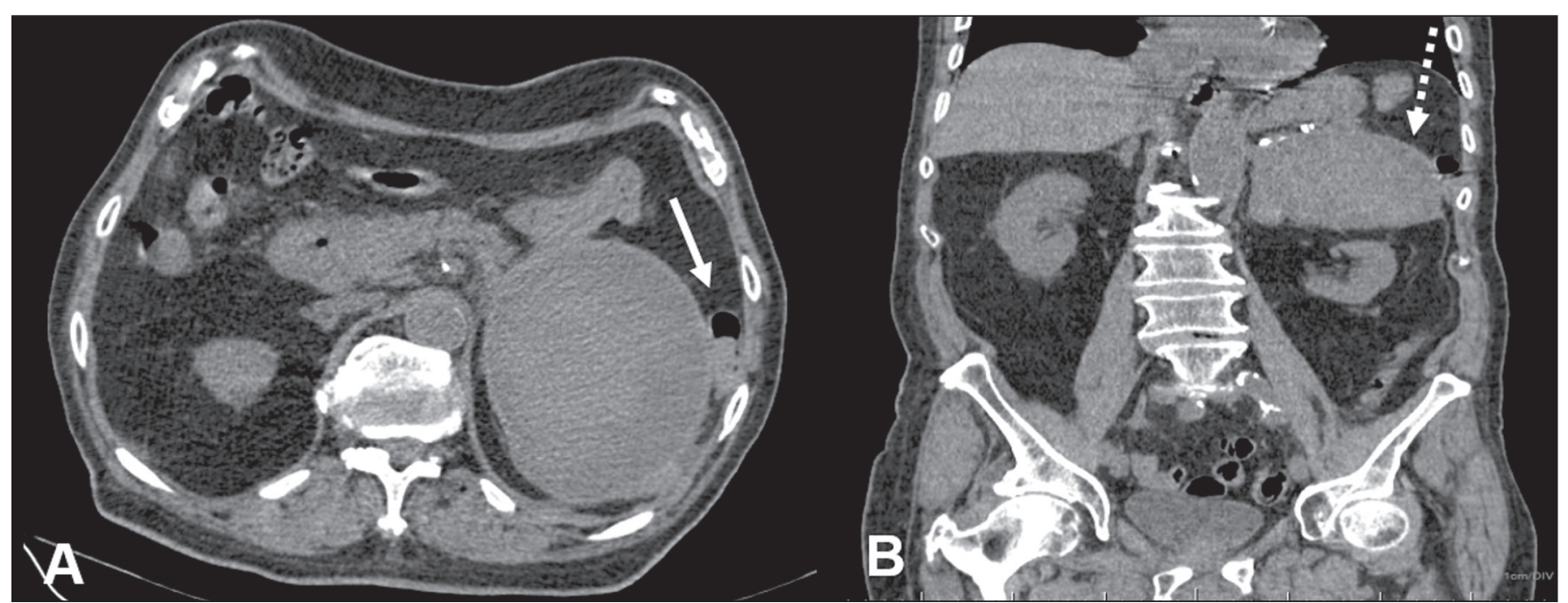

Figure 2. CT of the abdomen, showing a mass in the left adrenal gland, with regular, well-defined margins, measuring $12.5 \times 10.1 \times 7.7 \mathrm{~cm}$, and pre-contrast attenuation of $45 \mathrm{HU}$. A: Axial CT slice showing lateral displacement of the colonic segment (arrow). B: Coronal CT slice showing capsular enhancement (dotted arrow).

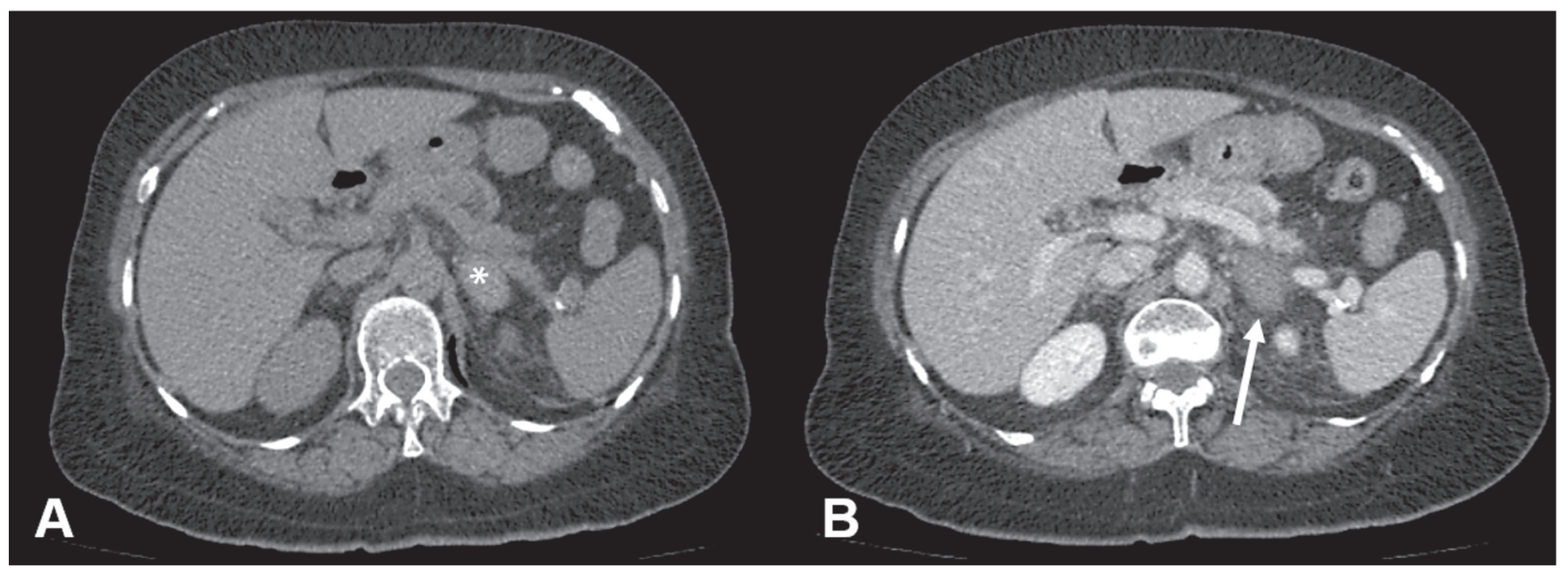

Figure 3. A: Noncontrast axial CT of the abdomen showing increased volume of the left adrenal gland, caused by a mass measuring $2.3 \times 2.6 \times 3.8 \mathrm{~cm}$, with regular, well-defined margins and attenuation of $53 \mathrm{HU}$ (asterisk). B: Axial CT scan after intravenous administration of contrast shows no enhancement (arrow). 


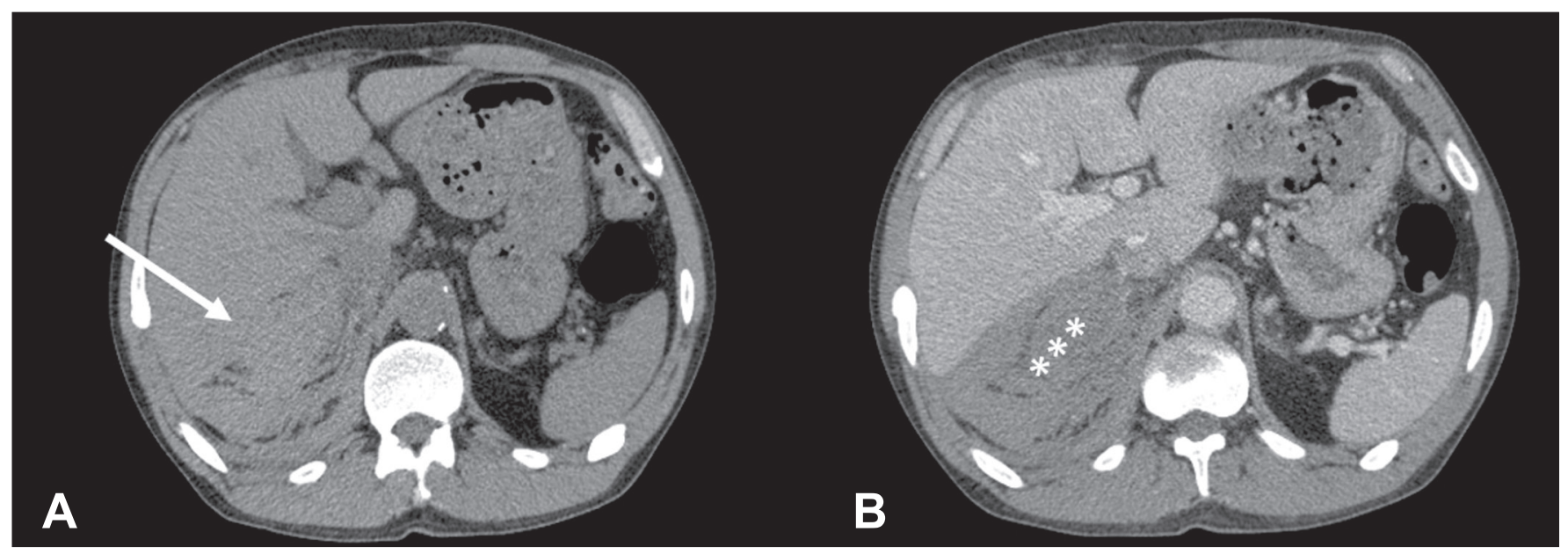

Figure 4. CT scan of the abdomen showing an irregular, poorly delimited mass in the right adrenal gland (A, arrow), with no enhancement after contrast administration $(\mathbf{B})$, measuring $6.0 \times 6.0 \times 4.0 \mathrm{~cm}$ (asterisks).

Table 2-Clinical history, etiology, and outcomes.

\begin{tabular}{|c|c|c|c|}
\hline Patient & Clinical history/status & Etiology & Outcome \\
\hline 1 & Post-cardiac catheterization shock. Normal hemoglobin & Post-catheterization & Corticosteroid therapy \\
\hline 2 & Palpable abdominal mass & Hemophilia & Watchful waiting \\
\hline 3 & Hypertensive peak & Arterial hypertension & Watchful waiting \\
\hline 4 & Pneumonia and sepsis & Sepsis & Death \\
\hline 5 & Abdominal pain & Metastasis of hepatocellular carcinoma & Surgical resection \\
\hline 6 & Dialysis-dependent chronic kidney disease and renal transplantation & Infection & Watchful waiting \\
\hline
\end{tabular}

causes include severe physical stress, infection, bleeding disorders, use of anticoagulants, procedures, and tumor bleeding ${ }^{(2,3,8,10)}$. There are two proposed mechanisms involved in the pathogenesis of idiopathic hemorrhages ${ }^{(11)}$ : stress and adrenal medullary venous thrombosis. Stress can develop due to recent surgical procedures, organ failure, sepsis, or pregnancy, none of which are mutually exclusive. Recognizing the importance of adrenal hemorrhage is particularly essential given the customary use of anticoagulants and the introduction of agents such as dabigatran. Adrenal hemorrhage may cause complications for procedures such as adrenal vein catheterization and biopsy. Although acute adrenal hemorrhage within an adrenal mass is most commonly observed in cases of pheochromocytoma, it has also been described in patients with myelolipoma, metastatic lesions, adrenocortical carcinoma, adenoma, or hemangioma ${ }^{(8,12)}$. In an earlier study, calcification suggestive of prior hemorrhage was observed in $26 \%$ of myelolipomas ${ }^{(13)}$, which rarely present clinically evident hemorrhage ${ }^{(8)}$.

The clinical features of adrenal hemorrhage are nonspecific, including abdominal pain, nausea, vomiting, hypotension, hypertension, low-grade fever, agitation, and decreased hematocrit ${ }^{(14)}$. Laboratory tests are of limited use in the evaluation of adrenal hemorrhages, because only massive bleeding can cause a drop in the level of hemoglobin/hematocrit and only large bilateral hemorrhage will affect adrenal function severely enough to lead to adrenal insufficiency. Consequently, imaging examinations play a fundamental role in diagnosis and, consequently, in the proper care of patients ${ }^{(15)}$.

With the increased use of sectional imaging methods, most adrenal masses are now detected as incidental findings in examinations requested for the investigation of other conditions. The majority of incidentally discovered adrenal formations are nonfunctioning adenomas. However, the adrenal gland is also commonly the site of metastases and hemorrhages, as well as, to a lesser degree, primary tumors (16). Differentiating between potentially malignant and benign lesions is essential, because metastases to the adrenal glands are common ${ }^{(17)}$, so much so that several studies are being developed in order to examine the issue ${ }^{(18-21)}$. Although adrenal hemorrhage is rare, its consequences are potentially fatal, especially if it is not diagnosed in a timely manner. Therefore, the radiologist must be familiar with the main imaging features of adrenal hemorrhage.

The imaging findings of adrenal hemorrhage are diverse ${ }^{(10)}$ and vary according to the time elapsed between the onset of bleeding and the imaging examination. In this context, several patterns have been described, including homogeneous or heterogeneous solid masses, masses with central liquid density, and retroperitoneal infiltration ${ }^{(21)}$. Although some of these patterns are diagnostic of adrenal hemorrhage, the appearance of a solid mass may be easily confused with adrenal neoplasia, particularly in a setting in which prior examinations are not available for comparison ${ }^{(15)}$. A mass with no calcified enhancement, a hemorrhagic pseudocyst, or an 
area of adrenal gland atrophy can be seen during the chronic bleeding phase, and complete spontaneous resolution is not uncommon $^{(10)}$.

Acute hemorrhage is characterized by the development of a mass, with hypoattenuation or heterogeneous attenuation, that fails to present enhancement after the infusion of contrast, in one or both of the adrenal glands. In most cases, normal adrenal enhancement is preserved and will often be distributed peripherally ${ }^{(9,22)}$. Other features that may be observed in acute adrenal hemorrhage include periadrenal infiltrate, active extravasation with retroperitoneal bleeding, and preservation of the normal shape of the adrenal gland ${ }^{(8)}$.

Noncontrast CT may be performed when there is clinical suspicion of adrenal hemorrhage or any contraindication to the intravenous administration of contrast, which may show an increase in adrenal volume with attenuation greater than that of the liquid, as well as periadrenal infiltrate $^{(8)}$.In cases of adrenal hemorrhage, the bleeding is often continuous until the gland expands beyond its normal shape, and a rounded or oval hematoma forms around the gland. Such hematomas vary in size from a few centimeters to more than $10 \mathrm{~cm}$. On CT, they are characterized as circular masses with no contrast enhancement and attenuation greater than that of the liquids. In some cases, conditions such as contrast extravasation during angiography, venous catheterization, or previous contrast infusion for cystography produce an appearance similar to that of acute adrenal hemorrhage, although the correlation with the clinical data can facilitate the distinction. Well-known granulomatous diseases, such as tuberculosis and histoplasmosis, may also present imaging manifestations similar to those of adrenal hemorrhage ${ }^{(8,12)}$.

When there is suspicion of adrenal disease in a patient with retroperitoneal hemorrhage, hemodynamic monitoring, preferably in an intensive care unit, is recommended $^{(23)}$. In patients with active bleeding, angiographic embolization is a valuable tool to achieve hemostasis. If the patient remains hemodynamically stable and asymptomatic after embolization, immediate surgical exploration is not necessary. However, if the condition of the patient deteriorates, surgical options should be considered ${ }^{(23)}$.

\section{CONCLUSION}

Adrenal hemorrhage is a rare clinical condition, with potentially fatal consequences due to acute adrenal insufficiency. Early diagnosis of acute adrenal insufficiency is crucial in order to administer the appropriate therapy in a timely manner.

It could be useful to recognize the CT findings described here-including that of a mass, with 45-65 HU of attenuation and without enhancement in the contrast phases, that alters the usual anatomy of the gland - as indicators of adrenal hemorrhage. However, given the limitations our study, specifically the small sample size, further, prospective studies are needed in order to corroborate our findings.

\section{REFERENCES}

1. Rao RH, Vagnucci AH, Amico JA. Bilateral massive adrenal hemorrhage: early recognition and treatment. Ann Intern Med. 1989; 110:227-35.

2. Saito T, Kurumada S, Kawakami Y, et al. Spontaneous hemorrhage of an adrenal cortical adenoma causing Cushing's syndrome. Urol Int. 1996;56:105-6.

3. Nakajo M, Onohara S, Shinmura K, et al. Embolization for spontaneous retroperitoneal hemorrhage from adrenal myelolipoma. Radiat Med. 2003;21:214-9.

4. Albert SG, Wolverson MK, Johnson FE. Bilateral adrenal hemorrhage in an adult. Demonstration by computed tomography. JAMA. 1982;247:1737-9.

5. Vella A, Nippoldt TB, Morris JC 3rd. Adrenal hemorrhage: a 25-year experience at the Mayo Clinic. Mayo Clin Proc. 2001;76:161-8.

6. Mehrazin R, Derweesh IH, Kincade MC, et al. Adrenal trauma: Elvis Presley Memorial Trauma Center experience. Urology. 2007; 70:851-5.

7. Baccot S, Tiffet O, Bonnot P, et al. Bilateral post-traumatic adrenal hemorrhage. Report of a case with acute adrenal insufficiency. Ann Chir. 2000; 125:273-5.

8. Jordan E, Poder L, Courtier J, et al. Imaging of nontraumatic adrenal hemorrhage. AJR Am J Roentgenol. 2012;199:W91-8.

9. Naqvi SA, Zaman S, Ahmed I. Spontaneous idiopathic unilateral adrenal haemorrhage (SIAH). J Coll Physicians Surg Pak. 2015;25 Suppl 1:S24-6.

10. Herr K, Muglia VF, Koff WJ, et al. Imaging of the adrenal gland lesions. Radiol Bras. 2014;47:228-39.

11. Hoeffel C, Legmann P, Luton JP, et al. Spontaneous unilateral adrenal hemorrhage: computerized tomography and magnetic resonance imaging findings in 8 cases. J Urol. 1995;154:1647-51.

12. Kawashima A, Sandler CM, Ernst RD, et al. Imaging of nontraumatic hemorrhage of the adrenal gland. Radiographics. 1999;19:949-63.

13. Kenney PJ, Wagner BJ, Rao P, et al. Myelolipoma: CT and pathologic features. Radiology. 1998;208:87-95.

14. Simon DR, Palese MA. Clinical update on the management of adrenal hemorrhage. Curr Urol Rep. 2009;10:78-83.

15. Rowe SP, Mathur A, Bishop JA, et al. Computed tomography appearance of surgically resected adrenal hematomas. J Comput Assist Tomogr. 2016;40:892-5.

16. Sacerdote MG, Johnson PT, Fishman EK. CT of the adrenal gland: the many faces of adrenal hemorrhage. Emerg Radiol. 2012;19:5360 .

17. Chojniak R. Imaging techniques in the characterization of adrenal lesions. Radiol Bras. 2014;47(6):v-vi.

18. Matos AP, Semelka RC, Herédia V, et al. Modified approach to the characterization of adrenal nodules using a standard abdominal magnetic resonance imaging protocol. Radiol Bras. 2017;50:19-25.

19. Schiavon LHO, Tyng CJ, Travesso DJ, et al. Computed tomographyguided percutaneous biopsy of abdominal lesions: indications, techniques, results, and complications. Radiol Bras. 2018;51:141-6.

20. Nunes TF. Percutaneous biopsy of abdominal lesions: what is currently the best diagnostic strategy? Radiol Bras. 2018;51(3):v-vi.

21. Mota MMS, Bezerra ROF, Garcia RT. Practical approach to primary retroperitoneal masses in adults. Radiol Bras. 2018;51:391-400.

22. Huelsen-Katz AM, Schouten BJ, Jardine DL, et al. Pictorial evolution of bilateral adrenal haemorrhage. Intern Med J. 2010;40:87-8.

23. Pushkar P, Agarwal A. Spontaneous massive adrenal hemorrhage: a management dilemma. J Endourol Case Rep. 2015;1:52-3. 